\title{
Outcome of pregnant women with previous cesarean section after sonographic assessment suggesting uterine dehiscence
}

\author{
Size $\mathrm{Wu}^{1}$ and Xiaojing $\mathrm{Cui}^{1}$ \\ ${ }^{1}$ the First Affiliated Hospital of Hainan Medical University
}

May 5, 2020

\begin{abstract}
Rationale, aims and objectives: Pregnant women at vaginal labor may occur uterine rupture, especially these who had previous caesarean section (CS). Lower uterine segment (LUS) dehiscence is different from uterine rupture, which may not cause serious event. The objective of this study was to investigate the outcome of pregnant women with previous caesarean section (CS) after sonographic evaluation revealing lower uterine segment (LUS) dehiscence. Methods: 107 pregnant women with previous CS and LUS thickness $<1.0 \mathrm{~mm}$ were recruited, the LUS and myometrium was measured, and ultrasound findings suggestive of uterine rupture were compared with findings at laparotomy. The included pregnant women were assigned into two groups, including 64 pregnant women had vaginal delivery at full-term and 43 pregnant women underwent repeat CS at preterm. Results: Ultrasound findings suggestive of uterine rupture and dehiscence were 18 and 89 women, respectively; 10 of them developed uterine rupture, and the incidence of uterine rupture was $9.34 \%$. The sensitivity, specificity, accuracy, positive and negative predictive values of ultrasound for the evaluation of LUS dehiscence and rupture were $100.00 \%, 91.75 \%, 92.52 \%, 55.56 \%$, and $100 \%$, respectively. There was no severe maternal obstetric complication, one fetus died, and the other fetuses were born with a 5-minute Apgar score of 7-10. Conclusions: Pregnant woman with previous CS and LUS myometrial thickness $<1.0 \mathrm{~mm}$ has higher risk of LUS rupture. LUS rupture is usually not catastrophic if it is managed timely. If there are no findings suggestive of LUS rupture by ultrasound, the gestation can sustain uneventfully to term under closely monitoring.
\end{abstract}

\section{Hosted file}

MS.doc available at https://authorea.com/users/291829/articles/419339-outcome-of-pregnantwomen-with-previous-cesarean-section-after-sonographic-assessment-suggesting-uterinedehiscence 

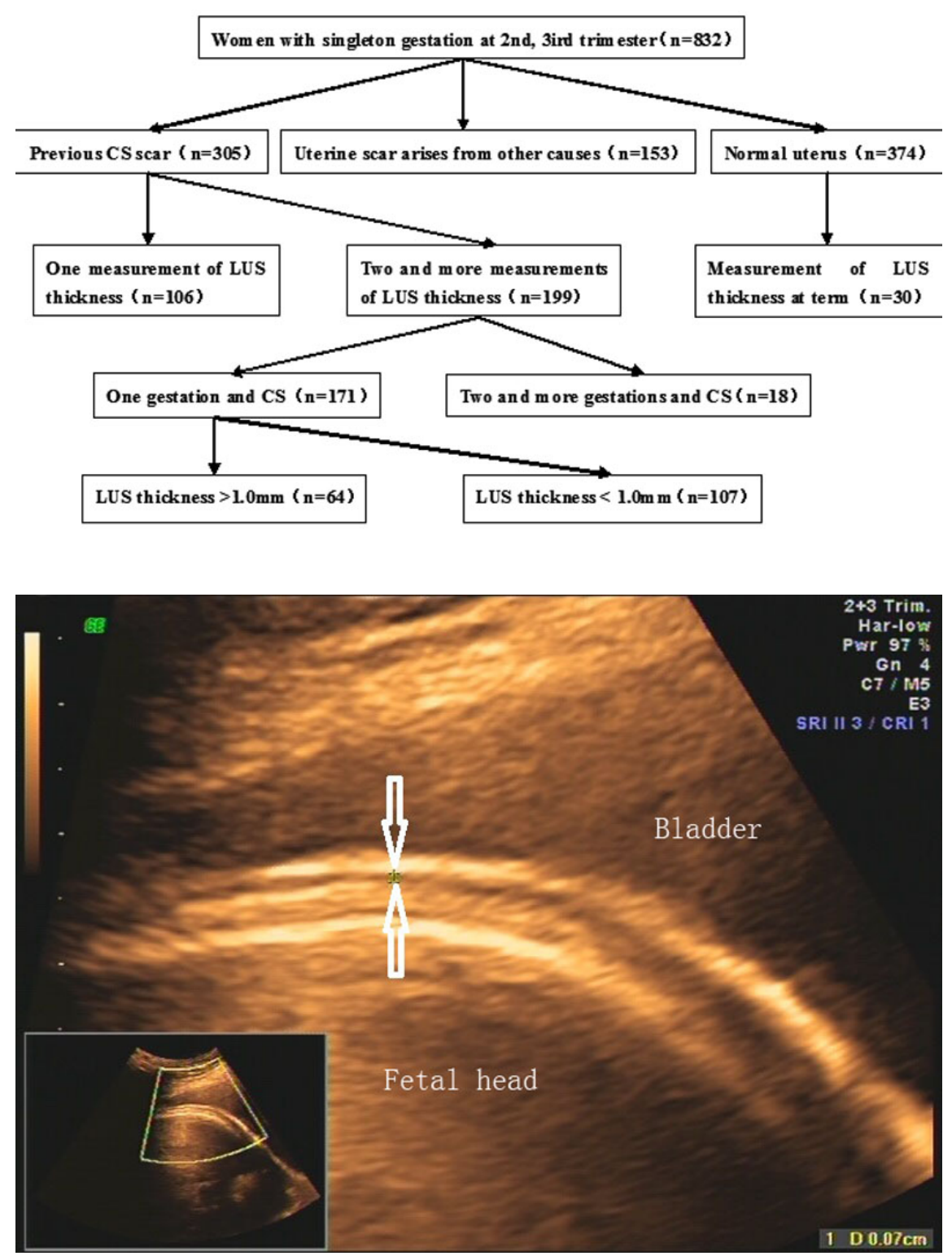

\section{Hosted file}

Table 1.doc available at https://authorea.com/users/291829/articles/419339-outcome-ofpregnant-women-with-previous-cesarean-section-after-sonographic-assessment-suggestinguterine-dehiscence

\section{Hosted file}

Table 2.doc available at https://authorea.com/users/291829/articles/419339-outcome-ofpregnant-women-with-previous-cesarean-section-after-sonographic-assessment-suggestinguterine-dehiscence

\section{Hosted file}

Table 3.doc available at https://authorea.com/users/291829/articles/419339-outcome-ofpregnant-women-with-previous-cesarean-section-after-sonographic-assessment-suggesting- 
uterine-dehiscence 